\title{
KARAKTERISTIK HABITUS DAN LINGKUNGAN POHON SARANG SEMUT RANGRANG (Oecophylla smaragdina) DI BANDAR LAMPUNG
}

\author{
Dewi Ariska ${ }^{1)}$, Suratman Umar ${ }^{1)}$, Nismah Nukmal ${ }^{1)}$ dan M. Kanedi ${ }^{1)}$ \\ 1) Jurusan Biologi Fmipa Universitas Lampung \\ Jl. Prof. Dr. Soemantri Brodjonegoro No. 1 Bandar Lampung 35145 \\ e-mail :dewiariska874@gmail.com
}

\begin{abstract}
The weaver ant (Oecophylla smaragdina) is a eusocial insect, whose colonic life is highly dependent on the existence of trees. The existence of the weaver ant in natural habitat is now reduced due to the destruction of habitats caused by humans. To preserve the existence of weaver ant in nature needs to be studied bioecology as the purpose of this research is to know the characteristics of habitus and environment of weaver ants nest in Bandar Lampung. The research was conducted in June-October 2017 at the location of yard and plantation, using 50\% sample from the sample population, from 20 districts in Bandar Lampung, 10 sub-districts were used as randomly selected research sites. The results showed as many as 15 types of plants used weaver ant for nesting. The most widely planted species of weaver ant is Mangifera sp. with characteristics of slippery surface habitus, sympodial branching, tree height of 3.9 to $11.5 \mathrm{~m}$ and an average canopy of $>65 \%$, more nests found in yards (76\%) far from urban areas, the percentage of the dominant nest toward the east, which is $41.8 \%$ of the total number of 86 nests.
\end{abstract}

Keywords: Weaver ant, yard, plantation, Mangifera sp., Habitus

\section{PENDAHULUAN}

Semut rangrang (Oecophylla smaragdina) termasuk serangga dalam ordo Hymenoptera, familiFormicidae. Terdapat dua spesies semut rangrang yaitu Oecophylla smaragdina yang tersebar dari India, Asia Tenggara sampai Australia dan $O$. longinoda yang tersebar di benua Afrika (Holldobler dan Wilson 1990).

Semut rangrang merupakan serangga eusosial (sosial sejati), dan kehidupan koloninya sangat tergantung pada keberadaan pohon (arboreal). Semut rangrang membentuk sarang di bagian tajuk pohon.Sarang dibentuk dari jalinan beberapa helai daun muda dengan menggunakan sutera yang dikeluarkan dari mulut larva.Sarang bersifat polydomous artinya satu koloni mendiami banyak sarang dalam satu pohon atau dalam pohon yang berbeda.Dalam satu sarang dapat ditemukan ratusan sampai ribuan semut pekerja, (Holldobler dan Wilson, 1990).

Semut rangrang bersifat predator dan ag- resif, karena sifatnya ini semut rangrang sering digunakan sebagai agen pengendalian biologi(Lim dan Kirton, 2001). Dari berbagai penelitian, semut rangrang digunakan sebagai agen biokontrol di Afrika pada tanaman perkebunan seperti kelapa dan kakao, sedangkan di Asia dan Australia pada pertanaman buah-buahan dan kacang kacangan (Way dan Khoo, 1992)

Sebuah arsip dari Cina bagian selatan memperlihatkan bahwa sarang semut rangrang dipanen, dijual dan diletakkan di pohon jeruk untuk memberantas serangga hama sejak lebih dari 1.000 tahun yang lalu. Populasi semut rangrang yang tinggi dapat mengurangi permasalahan hama tungau dan hama penggerek daun (Falahudin, 2012).

Berdasarkan fakta tercatat pada tahun 1999 - 2006 merupakan masa melimpahnya semut rangrang. Pada saat itu banyak perkebunan buah terselamatkan dari serangan hama, seperti hama ulat karena hama - hama tersebut adalah makanan utama dari semut rangrang. Fenomena ulat bulu yang pernah terjadi di 
Indonesia pada bulan November 2010 sampai Juni 2011 tidak menyerang Kebun Raya Bogor karena di dalamnya terdapat koloni semut rangrang. Namun kini populasinya semakin menurun bahkan di alam sudah semakin langka disebabkan habitat utamanya yaitu pohon dan hutan dialih fungsikan sebagai industri dan permukiman, juga adanya perburuan kroto secara besar-besaran tanpa memperhatikan populasi (LIPI, 2012).

Sistem perkebunan yang menggunakan pestisida merupakan salah satu faktor penyebab ketidakseimbangan ekosistem, terutama habitat alamiah serangga. Hasil penelitian Fayle et al. (2010) di Malaysia menunjukkan bahwa struktur dan komposisi semut berubah secara linier terhadap perubahan lahan, aplikasi pestisida juga mempengaruhi keanekaragaman serangga (Wanger et al., 2010), termasuk musuh alami dan serangga berguna lain seperti semut rangrang, serta memicu terjadinya resistensi hama seperti wereng dan ulat (Matsumura dan Morimura, 2010).

Keberadaan semut rangrang ini sangat penting dalam pengendalian hama tanaman perkebunan tetapi populasinya di alam sudah semakin menurun dan sampai saat ini belum ada informasi dan data data yang menjelaskan karakteristik habitus dan pohon yang digunakan semut rangrang untuk membangun sarang, sehingga diperlukan studi awal untuk mengetahui karakteristik habitus dan lingkungan pohon sarang semut rangrang di alam. Dengan mengetahui karakteristik habitus dan pohon apa saja yang disukai oleh semut rangrang untuk bersarang, diharapkan dapat digunakan sebagai upaya melestarikan semut rangrang di alam.

\section{METODE PENELITIAN}

Penelitian ini telah dilaksanakan pada bulan Juni sampai Oktober 2017 di 10 kecamatan di kota Bandar Lampung.Alat yang digunakan dalam penelitian ini adalah kamera dipergunakan untuk dokumentasi, meteran roll dipergunakan untuk mengukur diameter pohon, penggaris untuk mengukur panjang dan lebar daun, kompas, lembar data dan alat tulis untuk menulis data yang diperoleh, dan untuk menaksir tinggi pohon menggunakan aplikasi android bernama Smart Measure, aplikasi ini bisa digunakan untuk kehidupan sehari-hari seperti mengukur tinggi pohon, mengukur luas lahan atau mengukur jarak.

Penentuan lokasi penelitian menggunakan metode random sampling. Penelitian ini menggunakan $50 \%$ sampel dari jumlah populasi sampel (kecamatan dan kelurahan), dari 20 kecamatan di Bandar lampung digunakan 10 kecamatan sebagai lokasi penelitian, kecamatan yang teracak yaitu kecamatan Rajabasa, Kemiling, Teluk betung Selatan, Labuhan Ratu, Teluk betung barat, Sukarame, Way Halim, Kedamaian, Tanjung karang barat, Tanjung Karang Pusat. Lokasi yang diamati meliputi lokasi pekarangan dan perkebunan.Paramater yang diamati yaitu tinggi poho, diameter batang, kanopi, morfologi daun (panjang, lebar dan permukaan daun), junlah dan arah sarang.Data yang didapat dianalisis secara deskriptif yang kemudian disajikan dalam bentuk tabel dan foto.

\section{Hasil dan Pembahasan}

Dari survei yang telah dilkukan di 10 kecamatan di Bandar Lampung berikut ini jenis - jenis tumbuhan dan karakteristik habitus dari tumbuhan sarang semut rangrang disajikan pada Tabel 1 berikut : 
33 / Ariska D., S. Umar, N. Nukmal, M. Kanedi

Tabel 1. jenis - jenis tumbuhan dan karakteristik habitus dari tumbuhan sarang semut rangrang.

\begin{tabular}{|c|c|c|c|c|c|c|c|c|c|c|}
\hline \multirow[t]{2}{*}{ No } & \multirow[t]{2}{*}{ Jenis Tumbuhan } & \multicolumn{7}{|c|}{ Karalteristik habitus } & \multicolumn{2}{|c|}{$\sum$ Pohon pada lokasi } \\
\hline & & $\begin{array}{l}\text { Tinggi } \\
\text { pohon } \\
(m)\end{array}$ & $\begin{array}{c}\text { Diamater } \\
\text { batang } \\
\text { (cm) }\end{array}$ & $\begin{array}{l}\text { Kanopi } \\
(\%)\end{array}$ & $\begin{array}{c}\text { Tipe } \\
\text { percabangam }\end{array}$ & $\begin{array}{l}\text { Panjang } \\
\text { daun } \\
(\mathrm{cm})\end{array}$ & $\begin{array}{l}\text { Lebar } \\
\text { daun } \\
(\mathrm{cm})\end{array}$ & $\begin{array}{l}\text { Permukaan } \\
\text { daun }\end{array}$ & Pekarangan & Perkebunan \\
\hline 1. & Mangga (Mangifera sp.) & $4-11,5$ & $15,2-9,5$ & 65.75 & Simpodial & $21 \cdot 30$ & 5.9 & Licin & 7 & 1 \\
\hline 2. & Mahoni(Swetenia mahagoni) & 11,1 & 16,8 & 55 & Monopodial & 17.23 & 5.10 & Mengkilap & 1 & \\
\hline 3. & $\begin{array}{l}\text { Kerai Payung (Filicium } \\
\text { decipiens) }\end{array}$ & $14,9 \cdot 16,4$ & $24,8-31,5$ & 85 & Simpodial & $8,2 \cdot 25$ & $4,2 \cdot 6$ & Mengkilap & 2 & \\
\hline 4. & Ketapang (Terminalia catappa) & 11,6 & 24,8 & 65 & Monopodial & 17.30 & 15.20 & Licm & 1 & \\
\hline 5. & Kopi (Coffea sp.) & $3,3-3,5$ & $4,7 \cdot 5,1$ & 45 & Simpodial & $15 \cdot 19$ & $7 \cdot 10$ & Mengkilap & & 2 \\
\hline 6. & Sirsake(Annona muricata & 7,5 & 10,3 & 75 & Monopodial & $12-15$ & $5-6,5$ & Mengkilap & 1 & \\
\hline 7. & Durian (Durio zibethinus) & 8,5 & 21,6 & 75 & Simpodial & $11,5 \cdot 17$ & 4.7 & Mengkilap & 1 & \\
\hline 8. & Salam (Syzgium pobianthum) & 4,2 & 4,7 & 15 & Simpodial & $10 \cdot 13$ & $4,5 \cdot 6$ & Licin & 1 & \\
\hline 9. & Kelengkeng (Dimocarpus longan) & 7,3 & 11,7 & 75 & Simpodial & 9.15 & $4-6,5$ & Mengkilap & 1 & \\
\hline 10. & Duku(Lansiwn domesticum) & 4,2 & 10,2 & 45 & Monopodial & $16 \cdot 21$ & 9.14 & Mengkilap & 1 & \\
\hline 11. & $\begin{array}{l}\text { Jengkol(Archidendron } \\
\text { pauciflorum) }\end{array}$ & 18,7 & 24,8 & 75 & Simpodial & $11 \cdot 19$ & 6.14 & Mengkilap & & 1 \\
\hline 12. & Alpukat (Persea mill) & 13,7 & 24,8 & 85 & Simpodial & $10 \cdot 15$ & 6.9 & Mengkilaap & 1 & \\
\hline 13. & Discoreasp. & $1-1,7$ &. & . & & & $6,5-11$ & Kasap & 1 & \\
\hline 14. & Solandriasp. & Perdu & & 5 & Simpodial & 7.11 & 4.6 & Mengkilap & & 2 \\
\hline 15. & Jambu air (Syzygium aquewon) & 12,8 & 28,6 & 75 & Simpodial & $15 \cdot 20$ & 5.10 & Mengkilap & 1 & \\
\hline \multicolumn{9}{|c|}{ Total } & $\begin{array}{c}19 \\
(76 \%) \\
\end{array}$ & $\begin{array}{c}6 \\
(24 \%)\end{array}$ \\
\hline
\end{tabular}

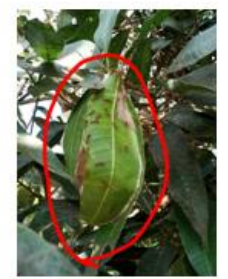

(a)

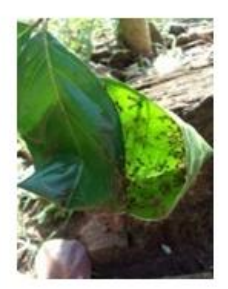

(f)

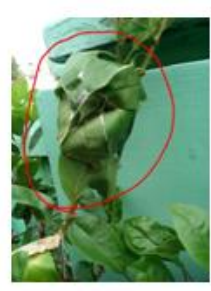

(k)

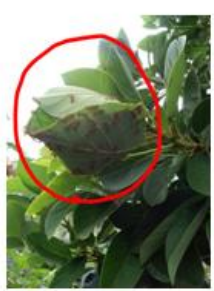

(b)

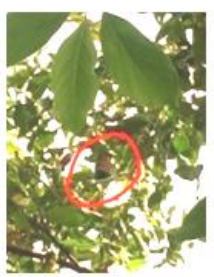

(g)

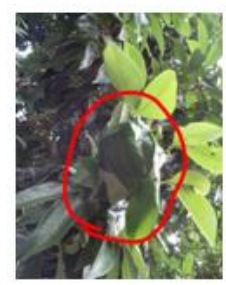

(1)

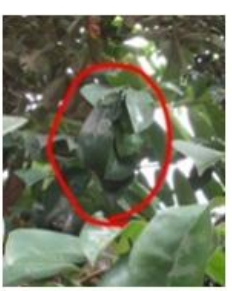

(c)

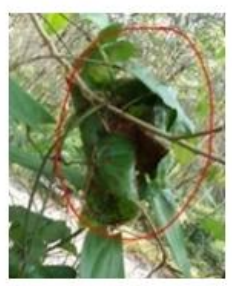

(h)

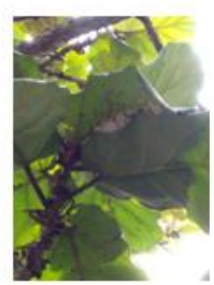

(m)

(d)

(i)
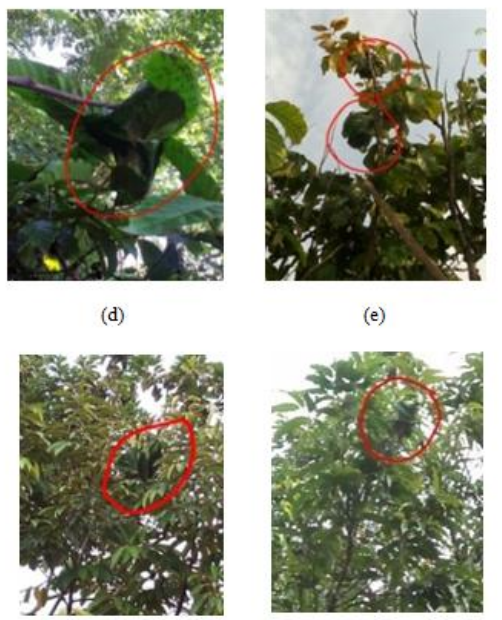

(e)

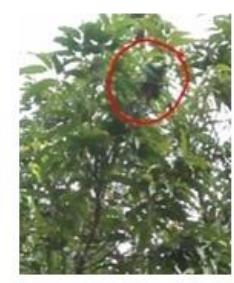

(j)

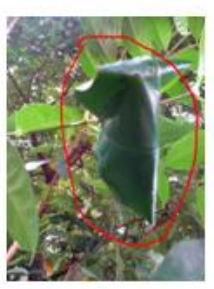

(n)

Gambar 1.Jenis tumbuhan sarang semut rangrang yang ditemukan di Bandar lampung.

Keterangan :a) Mangifera sp., b) Persea mill., c) Annona muricata., d) Coffea sp.,

e) Lansium domesticum., f) Archidendron pauciflorum., g) Syzygium aqueum., h) Discorea sp., i) Durio zibethinus., j) Filicium decipiens., k) Solandria sp., I) Dimocarpus longan., m) Dimocarpus longan., n) Syzgium polyanthum. 
Dari hasil pengamatan yang telah dilakukan ditemukan sebanyak 15 jenis tumbuhan yang digunakan semut rangrang untuk bersarang yaitu pohon kelengkeng, sirsak, salam, kopi, durian, alpukat, mangga, tajung, ketapang, jengkol, duku, jambu air, mahoni, bunga terompet (Solandria sp.) dan tumbuhan menjalar/ uwi (Discorea sp.). Sarang semut rangrang dominan ditemukan dilokasi pekarangan yang minim ganguan manusia, yakni dari 25 tumbuhan sarang semut rangrang sebayak 19 tumbuhan berlokasi di pekarangan sedangkan 6 tumbuhan berlokasi di perkebunan

Jenis pohon yang mendominasi yaitu pohon mangga sebanyak 8 pohon dari jumlah keseluruhan 15 jenis tumbuhan. Karakteristik pohon mangga yang digunakan semut rangrang untuk membangun sarang yaitu permukaan daun licin, panjang daun $21-30 \mathrm{~cm}$ dan lebar daun $5-9 \mathrm{~cm}$ dengan diameter pohon $21,2-29,5 \mathrm{~cm}$, percabangan simpodial, tinggi pohon 3,9 - 11,5 m serta rata - rata kanopi $>65 \%$.

Dari karakteristik habitus yang sudah dibahas di atas, dapat dilihat bahwa rata - rata habitus yang ditemukan berupa pohon, namun saat survei di lapangan dijumpai juga sarang semut rangrang pada tumbuhan perdu, tumbuhan perdu yang ditemukan yaitu bunga terompet (Solandria sp.). Selain pohon dan tumbuhan perdu sarang semut rangrang juga ditemukan pada tumbuhan menjalar/uwi (Discorea sp.) tumbuhan ini memiliki panjang daun $16-24 \mathrm{~cm}$ dan lebar 6,5 - $11 \mathrm{~cm}$, permukaan daun kasap .Selain jenis pohon dan karakteristik habtius pohon saat pengamatan juga dicatat jumlah dan arah sarang.

Persentase arah sarang dominan ke timur, yakni sebesar $41,8 \%$ dari total jumlah 86 sarang sedangkan persentase arah sarang terkecil yakni ke barat sebesar $0 \%$, hal ini terjadi dengan akifitas semut rangrang dalam membangun sarang, saat membangun sarang semut rangrang akan merajuthelaian daun dengan bantuan benang su-

Hasil pengamatan tersebut disajikan pada Tabel 2.

\begin{tabular}{lll}
\hline Arah & $\sum$ Sarang & $\%$ \\
\hline Timur & 36 & 41,8 \\
\hline Tenggara & 17 & 19,7 \\
\hline Selatan & 2 & 2,3 \\
\hline $\begin{array}{l}\text { Barat } \\
\text { daya }\end{array}$ & 6 & 6,9 \\
\hline Barat & 0 & 0 \\
\hline Barat laut & 3 & 3,4 \\
\hline Utara & 9 & 10,4 \\
\hline Timur laut & 13 & 15,1 \\
\hline Total & 86 & \\
\hline
\end{tabular}

tra yang dikeluarkan oleh larva (Holldobler dan Wilson, 1990) dan dicampur dengan feromon dari mulut semut rangrang dewasa kemudian rajutan dari helaian daun ini dikeringkan dengan bantuan sinar matahari. Maka dari itu sarang yang ditemukan di lapangan dominan ke arah timur (terbitnya matahari ) karena semut rangrang membutuhkan panas yang cukup untuk membangun sarang.

Selain itu semut rangrang dalam aktifitasnya lebih aktif di siang hari, sesuai dengan penelitian Harlan 2006, yang menyatakan bahwa aktivitas semut rangrang sepanjang waktu, tetapi aktivitas diurnal lebih dominan dibandingkan nokturnal, hasil penelitianya menunjukan aktifitas pencarian makan tertinggi terjadi pada kisaran pukul. 09.00-11.00 dan pukul $14.00-15.00$.

\section{KESIMPULAN}

Jenis tumbuhan yang digunakan semut rangrang untuk bersarang ditemukan sebanyak 15 jenis tumbuhan, pohon mangga paling banyak ditempati sarang semut rangrang dengan karakteristik habitus permukaan daun licin, percabangan simpodial, tinggi pohon 3,9 - 11,5 m serta rata - rata kanopi > 65\%, 
sarang lebih banyak ditemukan di pekarangan (76 \%) yang jauh dari perkotaan, persentase arah sarang dominan ke timur, yakni sebesar 41,8\% dari total jumlah 86 sarang.

\section{SARAN}

Perlu dilakukan penelitian lebih lanjut mengenai intensitas panas matahari yang dibutuhkan semut rangrang untuk membangun sarang pada musim hujan dan musim kemarau.

\section{DAFTAR PUSTAKA}

Falahudin I, 2012.Peranan Semut Rangrang (Oecophylla smaragdina) dalam Pengendalian Biologis pada Perkebunan Kelapa Sawit.IAIN Raden Patah. Palembang. dalamhhtp:/digilib.iinsby.ac.id/7542/1/ buku 6 fix_7.pdf diakses pada tanggal 05 januari 2017.

Fayle, T.M., Bakker, L., Tan M., Alexandra, Francesca, Kai L., Luangyotha, Phouthakone, Bruno H., Palmeirim, Ana F.,Paninhuan., Sebastian K., Sam, P.T., Paul G.,Trevelyan, R. 2010. A positive relationship between ant biodiversity and predatory function across a disturbance gradient in a Asian rain forest. Journal Myrmecological News 14: 5-12.

Harlan, I. 2006. Aktivitas Pencarian Makan dan Pemindahan Larva Semut Rangang Oecophylla smaragdina (Formicidae: Hymenoptera). Jurusan Biologi. Fakultas Matematika dan IImu alam.Insitut Pertanian Bogor. Bogor.

Holldobler, B., dan Wilson, O.W. 1990. The Ants. Belknap Press. USA.
Lim G.T, dan Kirton, L.G. 2001. $A$ Prelimenary study on the prospects (Lepidoptera: Pyralidae), by ants(Hymenoptera: formicidae). dalam: Proceeding of the Conference on Forestry and Forest Product Research Tropical Forestry Research in the New Millenium: Meetings Demands and Challenges Kuala Lumpur.

[LIPI] Lembaga IImu Pengetahuan Indonesia.2012. Semut Oecophylla smaragdina Predator Unggul Pengendali Hama Tanaman dalam http://lipi.go.id/berita/single/SemutOecophylla-smaradigna-F-PredatorUnggul-Pengendali-Hama-

Tanaman/7547.diakses pada tanggal 06 Januari 2017.

Matsumura, M., dan Morimura, S . 2010. Recent status of insecticide resistance in asian rice planthoppers. Journal Japan Agriculture.44 : 225 - 230

Van, M.V., dan Cuc, N.T.T. 2007.Ants As Friend. $\mathrm{CAB}$ International.Engham, UK.

Wanger, T.C., Rauf, A., dan Schwarze, S. 2010. Pesticides and tropical biodiversity .Journal Frontiers in Ecology and the Environment 8: 178179.

Way, M.J., dan Khoo, K.C. 1992. Role of Ants in Pest management. Annual Review of Entomology 37 : 479 - 503. 